\title{
Development and testing of a weather-based model to determine potential yield losses caused by potato late blight and optimize fungicide application
}

\author{
Alexey FILIPPOV, Maria KUZNETSOVA, Alexander ROGOZHIN, Olga IAKUSHEVA, Valentina DEMIDOVA, \\ Natalia STATSYUK (凶)
}

Laboratory of Potato \& Vegetable Diseases, All-Russian Research Institute of Phytopathology, Bolshie Vyazemy 143050, Russia

\begin{abstract}
Late blight is one of the most important potato diseases. To minimize yield losses, various protective measures are used including fungicide application. Active use of fungicides results in a contamination of the environment. Therefore, crop protection strategies optimizing the number of treatments are of great interest. Using information about late blight development in an experimental potato field recorded over 30 seasons, a simulator to forecast yield losses caused by the disease was developed based on the number of 5-d periods favorable for reinfection of plants during a vegetation season. The simulator was successfully verified using independent data on the disease development from nine unprotected potato fields in the Netherlands and Germany. The average difference between the calculated and real yield losses did not exceed 5\%. Using the simulator and weather data for a period of 2007-2017, yield losses were calculated for several areas of the Bryansk, Tambov, and Orenburg Regions of Russia. The results revealed differences in disease development between these regions and may be used to develop recommendations for a frequency of fungicide applications according to the regional risk of epidemics, leading to a significant reduction in fungicide use.
\end{abstract}

Keywords potato, late blight, Phytophthora infestans, yield losses, retrospective analysis, mathematical model

\section{Introduction}

Potato is included in the list of socially important products providing food security in Russia. Late blight, caused by the oomycete Phytophthora infestans, is one of the most

Received June 18, 2018; accepted August 17, 2018

Correspondence: nataafg@gmail.com damaging diseases of potato and a main reason for a pesticide use in this crop. Yield losses caused by this pathogen are determined by the destruction of plant tops resulting in a short crop and by the decay of infected tubers in the field or during storage. This disease alone does not produce any extensive tuber decay but is often accompanied by secondary infections causing rapid rotting of tubers. Late blight epidemics occur when there is a rapid repetition of infection cycles including pathogen penetration into a plant, development and propagation, and sporangia generation followed by infection of new plants. Under favorable conditions, every new generation of the pathogen may occur within 4-7 d. Each infection cycle produces thousands of spores and such disease outbreaks may cause huge yield losses.

Despite the considerable accumulated knowledge about this disease, late blight remains the major limiting factor for global potato production. In the absence of effective control of this disease, potato yield losses may reach $100 \%$. It is also considered that the use of infected tubers for food may cause some health problems ${ }^{[1]}$. Today the use of chemical fungicides is the most important component of an integrated protection of potatoes from late blight. Farmers can relatively easily control the disease via intensive application of fungicides. However, in Russia, as in many other countries, the high cost of fungicides limits their use. Chemical protection of crops also sometimes loses its effectiveness due to emergence of new pathogen strains, characterized by higher virulence and aggressiveness. This problem is often aggravated by the lack of any concepts of an adequate fungicide use strategy. Many Russian farmers start to apply fungicides only after clear manifestations of disease symptoms. As a rule, they apply 2-3 sprays with large intervals between applications, and do not care about achieving thorough coverage of all potato plants with fungicides. For seasons characterized by a low late blight incidence, farmers using such fungicide application strategy may achieve a reasonable harvest.

(c) The Author(s) 2018. Published by Higher Education Press. This is an open access article under the CC BY license (http://creativecommons.org/licenses/by/4.0) 
However, in seasons of a significant late blight development, such treatments are insufficient to control the disease. At the same time, agronomists of large potatogrowing companies often use a routine protection scheme with short intervals between pesticide applications to ensure late blight suppression. This strategy results in a large pesticide load entering the environment, and consumers demonstrate a great concern about food quality and environmental safety, focusing their attention on agricultural pesticides as possible toxicants ${ }^{[2]}$. Thus, underestimation of the blight severity causes yield losses, whereas overestimation involves unnecessary expense for control measures and possible contamination of the environment. This situation forces scientists to develop and implement new potato protection strategies, in which the number and frequency of fungicide applications should strictly correspond to the risk of a severe disease development.

Insufficient late blight control in commercial potato fields often results in infection of seed material. In Russia, about $80 \%$ of potatoes are grown on private plots and home gardens and may serve as an important source of infection. Unlike commercial potato producers, owners of such small plots usually do not apply any crop rotation, use non-certified seed material, and, as a rule, do not treat their potato with fungicides. We assume the inoculum does not represent a limiting factor for the development of epidemics in areas where potato is grown, and the impact of the disease on a tuber yield depends on weather conditions during a vegetation period.

The aim of this study was to develop an approach based on historical weather data for a certain potato-producing region to zone the average late blight severity on unprotected crops and, correspondingly, to determine the recommended necessity and frequency of local fungicide applications.

\section{Materials and methods}

\subsection{Place of observations and potato cultivars used}

In this work we used data obtained during a long-term field study (1972-2017) intended to observe late blight severity and its relationship with weather conditions. Observations were carried out at the experimental field of the AllRussian Research Institute of Phytopathology located in the Moscow Region. The field (0.6 ha) was planted with potato cultivars Sante (1972-2005) or Red Scarlett (20052017). Both cultivars are susceptible to late blight; their foliar blight resistance score was four out of nine according to the corresponding international scale ${ }^{[3]}$.

\subsection{Field experiment arrangement}

Experimental plots were arranged in four replications in the central part of the field. Each plot has an area of $28 \mathrm{~m}^{2}$ and consisted of four rows ( $10 \mathrm{~m}$ long by $0.7 \mathrm{~m}$ wide); the distance between planted tubers was $32 \mathrm{~cm}$. For each plot, only two internal rows were used for observations. During a growing season, late blight severity was assessed on a weekly basis starting from shoot emergence and continued until the senescence of the haulm; the evaluation was carried out using a common foliar blight assessment key ${ }^{[4]}$. Agrotechnical activity for the field corresponded to the usual local agricultural practices, excepting the absence of any fungicidal treatments.

\subsection{Yield loss calculation}

To evaluate epidemic severity, expected yield losses caused by late blight were calculated using a mathematic simulator developed earlier ${ }^{[5]}$. This simulator (Fig. 1) is based on the known hypothesis, which assumes a direct relationship between the yield losses and the area under disease progress curve (AUDPC) ${ }^{[6,7]}$.

Consistent with previous long-term observations ${ }^{[8]}$, this relation is expressed as Eq. (1):

$$
\omega=\frac{\mathrm{AUDPC}}{q} \times 100 \%
$$

where $\omega$ is a yield loss (\%) caused by an early foliage decay, AUDPC is an area under the disease progress curve, and $q$ is the number of days between the bud formation phase and the senescence of uninfected foliage. The average $q$ value for the early, intermediate, and mid-late potato cultivars was 46,52 and $84 \mathrm{~d}$, respectively. If the haulm was killed by frost or desiccation, or the harvesting was carried out before the natural death of the haulm, $q$ was considered to be equal to the number of days passed between a bud formation phase and the haulm killing. For a set of 219 independent late blight curves built in this study, the difference between the values of calculated and real yield losses did not exceed $9.8 \%$.

The real yield losses were determined under field conditions by a comparison of the potato yield harvested from untreated plots and plots treated with fungicides on a weekly basis.

\subsection{Evaluation of correlations between weather data and late blight severity}

As a rule, late blight epidemics occur as a result of a sequential repetition of several pathogen development cycles as described above. Under favorable conditions, every new generation of the pathogen may occur within 4-7 d. During a growing season, the process of late blight development consists of some sporadic population outbreaks resulting from reinfection of plants occurring under favorable weather conditions. Based on field experiments, a mathematical model was developed, which identified 


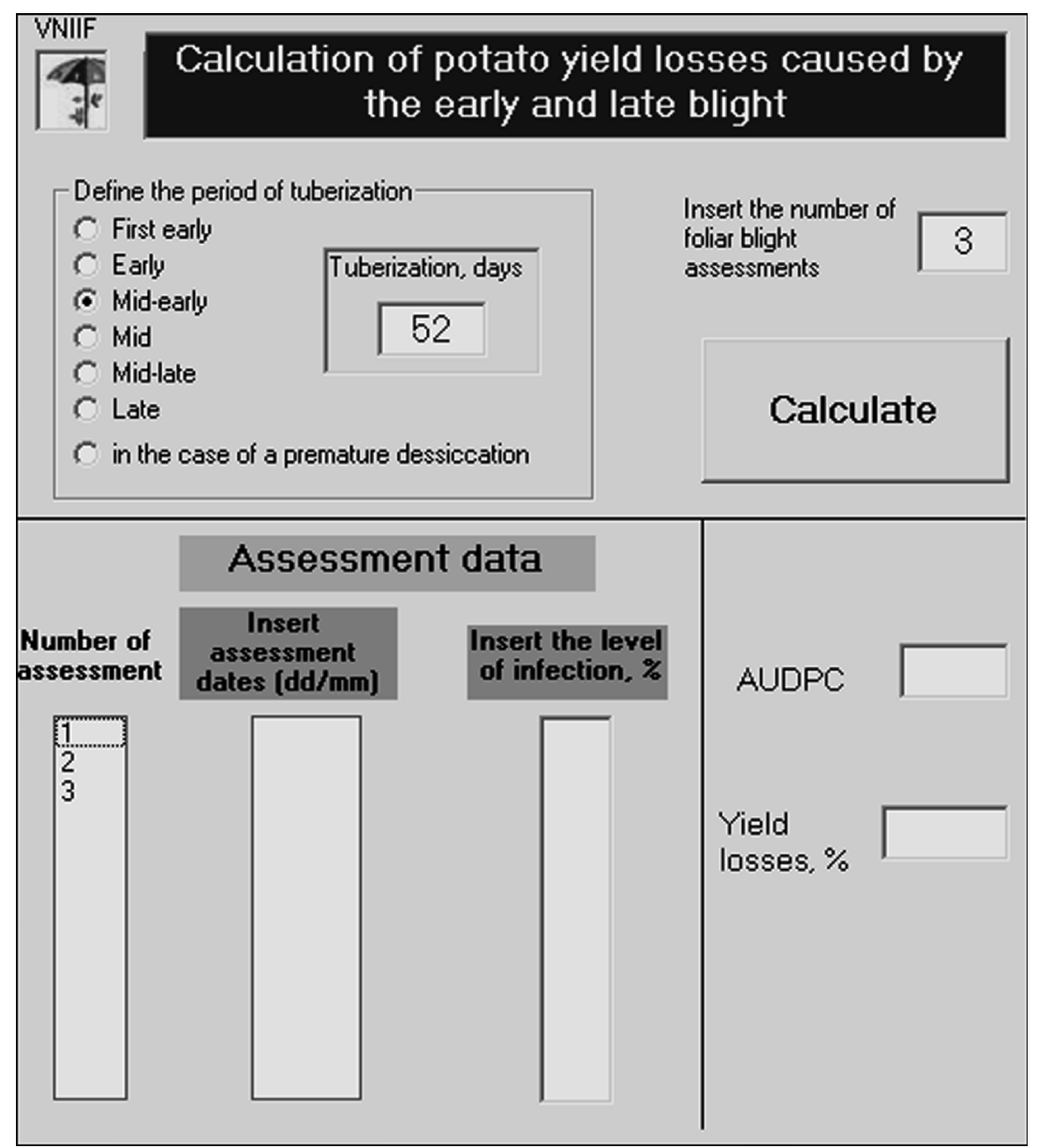

Fig. 1 Working window of a simulator program calculating potato yield losses caused by late blight development

weather "profiles", favorable or unfavorable for such outbreaks $^{[9,10]}$. To predict disease outbreaks, the use of weather data for every five consecutive days was used. The resulting dependence is described by Eqs. (2) and (3):

$$
\begin{aligned}
y_{1}= & -32.47+0.75 x_{1}+0.41 x_{2}+0.41 x_{3}+0.27 x_{4} \\
& +0.74 x_{5}+0.30 x_{6}-0.07 x_{7}-0.16 x_{8}+0.06 x_{9} \\
& +0.01 x_{10}+2.88 x_{11}+1.98 x_{12}+1.98 x_{13} \\
& +1.79 x_{14}+0.53 x_{15}
\end{aligned}
$$

and

$$
\begin{aligned}
y_{2}= & -31.34+0.63 x_{1}+0.37 x_{2}+0.42 x_{3}+0.22 x_{4} \\
& +0.65 x_{5}+0.24 x_{6}-0.06 x_{7}-0.15 x_{8}-0.13 x_{9} \\
& +0.15 x_{10}+4.88 x_{11}+3.55 x_{12}+3.34 x_{13} \\
& +2.50 x_{14}+2.29 x_{15}
\end{aligned}
$$

where $y_{1}$ and $y_{2}$ represent conditional variables, $x_{1,2,3,4,5}$ and $x_{6,7,8,9,10}$ are the day and night temperatures $\left({ }^{\circ} \mathrm{C}\right)$, respectively, considered in the weather forecast for the $1 \mathrm{st}$, 2nd, 3rd, 4th and 5th days of the 5-d period, and $x_{11,12,13,14,15}$ describe precipitations forecasted for the same five days, respectively. If $y_{1}<y_{2}$, the weather is favorable for reinfection of potato plants and, therefore, for the outbreak of the disease. If $y_{1}>y_{2}$, the weather is unfavorable for the reinfection. The working window of the simulator intended to reveal such periods is shown on Fig. 2, and it is considered that this model can be used to predict late blight severity.

\subsection{Verification of the developed simulator}

A quantitative relationship calculated by this simulator was verified using independent experimental data on late blight development obtained for nine unprotected potato fields near Lelystad (Netherlands) and Munich (Germany). These experimental data were obtained within the framework of the research program of the international EuroBlight consortium ${ }^{[11]}$. 


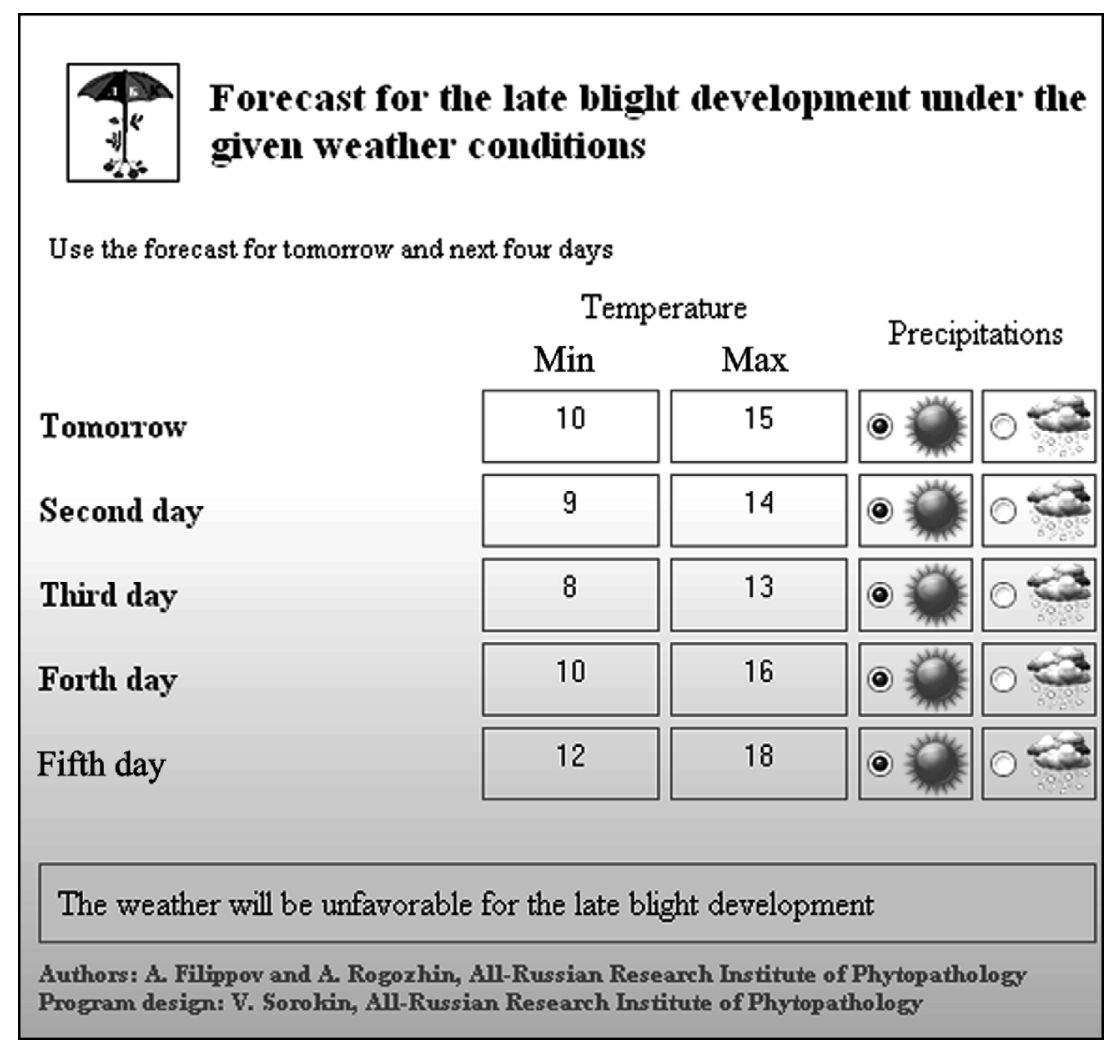

Fig. 2 Working window of a simulator program determining weather conditions favorable or unfavorable for late blight development

2.6 Evaluation of the effectiveness of the developed simulator for regions with different climatic conditions

The developed method was used to evaluate the average late blight severity in three different Russian regions, Bryansk, Tambov, and Orenburg Regions, located at the similar latitudes in the southwest, southern, and southeast parts of European Russia, respectively. The regions are characterized by different average amount of precipitation during a vegetation season: $220-230 \mathrm{~mm}$ for the Bryansk Region, 180-200 mm for the Tambov Region, and 120$130 \mathrm{~mm}$ for the Orenburg Region. For each region, we used weather data obtained in 2007-2017 from five standard weather stations controlling almost the whole territory of the region.

\section{Results and discussion}

During the period of observation of the experimental field, there was considerable variation in the actual calculated late blight severity between years (Fig. 3). Yield losses caused by the disease ranged from $1 \%(1972,1997$ and 2010) to 66\% (2013). During the first 15 seasons analyzed (up to 2002), the average yield losses were $18 \%$. For the next 15 seasons (2002-2017), this value increased to $33.6 \%$, which may be due to the increased frequency of rainy days observed in recent years in the Moscow Region and by a colonization of the field by more aggressive $P$. infestans populations.

According to our results, late blight severity during a growing season depends on the repeatability and distribution of 5-d periods with weather conditions favorable for reinfection $\left(y_{1}<y_{2}\right)$. The maximum correlation between yield losses and the frequency of these periods was observed during rapid plant growth, starting from the canopy closure stage and until beginning of flowering (Table 1, phase II). During this period, haulm mass doubled every $4-5 \mathrm{~d}$.

Table 1 Coefficients of correlation between the frequency of reinfection periods and potato yield losses caused by late blight calculated for different vegetative phases

\begin{tabular}{lc}
\hline Vegetative phase & Correlation coefficient \\
\hline I (Jun. 15 - Jul. 4) & -0.04 \\
II (Jul. 5 - Jul. 24) & 0.78 \\
III (Jul. 25 - Aug. 15) & -0.20 \\
\hline
\end{tabular}

The revealed dependence is described by Eqs. (4) and (5). If the number of 5-d periods favorable for reinfection between the stages of full shoots and complete haulm destruction exceeds eight, then yield loss is calculated 


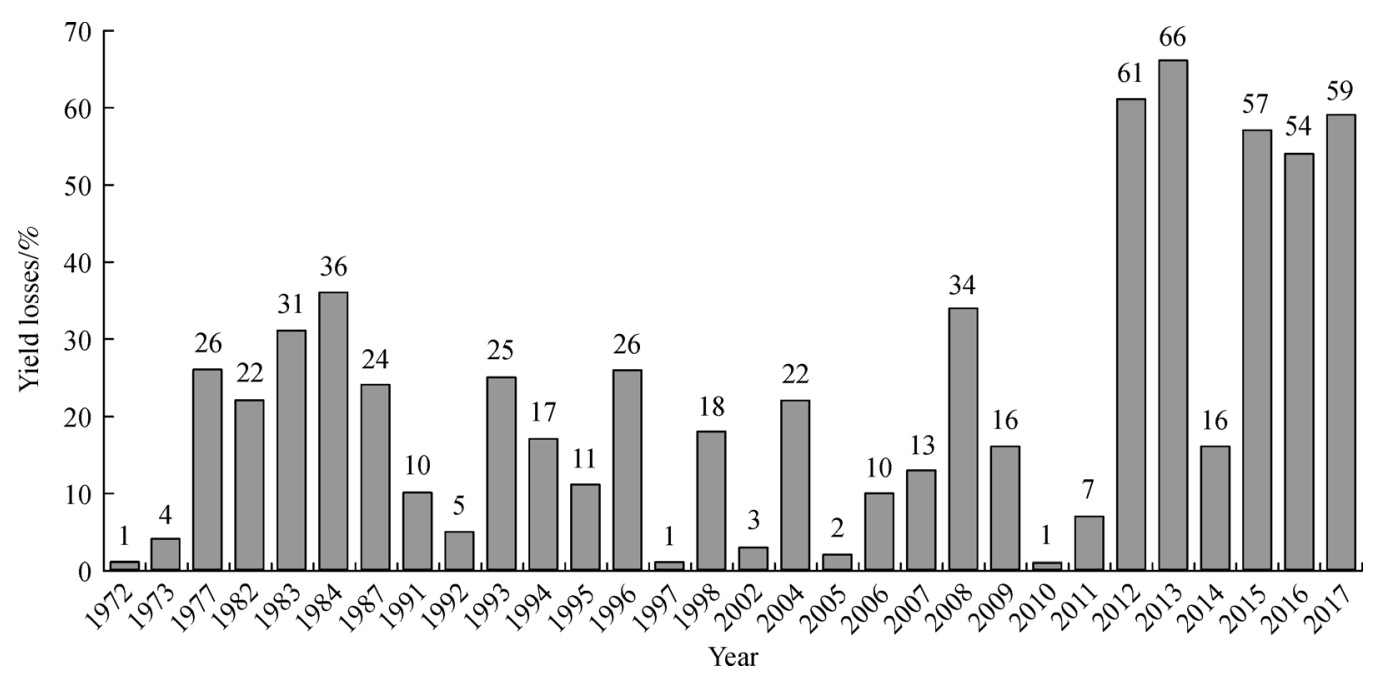

Fig. 3 Variation in late blight severity within the observed period (1972-2017, Moscow Region)

according to the following equation:

$$
\omega=0.8 \times(2.37+0.48 a+67 b)
$$

where $\omega$ is the yield loss caused by late blight (\%), $a$ is the number of 5-d periods with weather conditions favorable for plant reinfection as determined by Eqs. (2) and (3) $\left(y_{1}<y_{2}\right)$, and $b$ is the number of these periods, occurring during a rapid growth phase, normalized to the total number of such periods during the growing season.

If the number of such 5-d periods between the stages of full shoots and complete haulm destruction does not exceed eight, yield loss is calculated using a modified Eq. (4):

$$
\omega=0.8 \times(0.95 a+0.02)
$$

The calculated $R^{2}$ value for Eq. (5) is equal to 0.70 .

Verification of the algorithm based on Eqs. (4) and (5) was performed using independent experimental data for nine unprotected potato fields located near Lelystad (Netherlands) and Munich (Germany) and the open weather data for these geographical points. Real yield losses calculated using actual disease progress curves obtained for the considered seasons were compared with yield losses calculated by the above-described algorithm. For all fields included in the study, a deviation between the real yield losses and losses calculated using Eqs. (4) and (5) did not exceed 10\%; the average deviation value was $4.5 \%$ (Table 2).

The developed method for yield loss calculation was used to compare the late blight severity on potato fields of the Orenburg, Bryansk and Tambov Regions differing in average temperature and the humidity conditions. Results of a comparison of the late blight severity in these regions are shown in Table 3.

Our study is not the first in the field of investigation of interrelationships between weather conditions and late blight severity and there are a number of other publications devoted to this problem ${ }^{[12-14]}$. In a global scale, the severity of potato late blight was estimated by Hijmans, Forbes, and Walker, who used the Blitecast and Simcast disease forecast models ${ }^{[15]}$. Disease forecast models provide an indirect estimation of the late blight severity via the determination of the number of required fungicide applications as a function of some weather parameters. The algorithm described in this paper provides a calculation of

\begin{tabular}{|c|c|c|c|c|}
\hline \multirow{2}{*}{ Geographic location of data collection points } & \multirow{2}{*}{ Year } & \multicolumn{2}{|c|}{ Yield loss $/ \%$} & \multirow{2}{*}{$\begin{array}{l}\text { Deviation of actual from } \\
\text { calculated data/\% }\end{array}$} \\
\hline & & Actual $^{[11]}$ & Calculated $^{\mathrm{a}}$ & \\
\hline \multirow[t]{5}{*}{$\overline{\text { Munich (Germany) } 48^{\circ} 93^{\prime} \mathrm{N}, \mathrm{E} 11^{\circ} 55^{\prime} \mathrm{E}}$} & 2011 & 41 & 40 & -1 \\
\hline & 2012 & 32 & 42 & 10 \\
\hline & 2013 & 14 & 8 & -6 \\
\hline & 2014 & 40 & 35 & -5 \\
\hline & 2016 & 20 & 24 & 4 \\
\hline \multirow[t]{4}{*}{ Lelystad (Netherlands) $52^{\circ} 45^{\prime} \mathrm{N}, 5^{\circ} 53^{\prime} \mathrm{E}$} & 2011 & 49 & 50 & 1 \\
\hline & 2012 & 35 & 41 & 6 \\
\hline & 2014 & 26 & 33 & 7 \\
\hline & 2015 & 42 & 41 & -1 \\
\hline
\end{tabular}

Table 2 Comparison of actual and calculated yield losses for nine potato fields in Germany and Netherlands

Note: ${ }^{\text {a }}$ Data were calculated using the developed simulator (Eqs. (4) and (5)). 
Table 3 Late blight severity calculated for three regions of Russia (2007-2017)

\begin{tabular}{|c|c|c|c|c|c|}
\hline \multirow{2}{*}{ Region } & \multirow{2}{*}{ Area } & \multirow{2}{*}{ Average tuber yield loss $/ \%$} & \multicolumn{3}{|c|}{ Frequency of seasons with the corresponding yield losses } \\
\hline & & & $<10 \%$ & $10 \%-30 \%$ & $>30 \%$ \\
\hline \multirow[t]{6}{*}{ Bryansk } & Bryansk & 21.2 & 18.2 & 54.5 & 27.3 \\
\hline & Krasnogorsk & 20.5 & 36.4 & 45.5 & 18.2 \\
\hline & Zhukovsk & 19.4 & 36.4 & 36.4 & 27.3 \\
\hline & Navlinsk & 21.8 & 36.4 & 45.5 & 18.2 \\
\hline & Trubchevsk & 9.8 & 63.6 & 27.3 & 9.1 \\
\hline & Mean & 18.5 & 38.2 & 41.8 & 20.0 \\
\hline \multirow[t]{6}{*}{ Tambov } & Zherdevka & 6.4 & 90.9 & 0.0 & 9.1 \\
\hline & Kirsanov & 10.5 & 72.7 & 18.2 & 9.1 \\
\hline & Michurinsk & 10.7 & 72.7 & 18.2 & 9.1 \\
\hline & Morshansk & 11.7 & 72.7 & 9.1 & 9.1 \\
\hline & Tambov & 9.8 & 81.8 & - & 18.2 \\
\hline & Mean & 9.8 & 78.2 & 11.4 & 10.9 \\
\hline \multirow[t]{6}{*}{ Orenburg } & Orenburg & 1.5 & 100.0 & - & - \\
\hline & Buguruslan & 2.7 & 100.0 & - & - \\
\hline & Sorochinsk & 2.8 & 100.0 & - & - \\
\hline & Akbulaksk & 1.4 & 100.0 & - & - \\
\hline & Svetlinsk & 1.3 & 100.0 & - & - \\
\hline & Mean & 1.9 & 100.0 & - & - \\
\hline
\end{tabular}

the late blight impact on the yield based on the retrospective analysis of weather data; this impact is expressed via the percentage of yield losses determined for an unprotected potato field. In addition, this algorithm allows a user to estimate losses in the value of produced potato, which may arise in such situations.

The averaged data for the Bryansk and Tambov Regions revealed differences in late blight development: late blight severity also varied in different parts of the same region. For example, the average annual losses of potato and the frequency of seasons with high yield losses $(>30 \%)$ in Trubchevsk were almost threefold lower than those for other areas of the Bryansk Region. In contrast to the Bryansk and Tambov Regions, potato yield losses caused by late blight development in the Orenburg Region were not economically significant. Therefore, application of a routine scheme of frequent fungicidal treatments in potatogrowing areas of this region would be unnecessary.

Thus, based on a long-term study of the late blight development in one field, an algorithm was successfully developed for the yield loss calculation depending on the seasonal weather conditions. The use of this algorithm provides the possibility of determining a risk of a severe late blight development for an area based on the existing weather data; the accuracy of the method is quite high, with the average difference between the real and calculated values below 5\%. Application of the developed algorithm for the analysis of weather data for three regions differing in their climatic conditions demonstrated a possibility to distinguish regions with a high or low risk of epidemics and to develop the corresponding recommendations for the mode of fungicide applications intended to provide the necessary protection level and, at the same time, preventing excessive use of fungicides and reducing pesticide load. This may help farmers and their consultants to choose the best management practice for disease control suitable for their location: either application of the routine scheme of fungicide treatments, or the use of decision support systems based on forecasting models. The use of our algorithm may optimize costs for protective treatment and improve the total yield of potato.

In our further work, we plan to use this approach to assess the impact of the late blight on potato yield losses in all regions of the potato-growing zone of Russia. The implementation of the resulted data will allow farmers to better understand the risks of making wrong decisions and, in some cases, to significantly reduce the number of fungicide applications.

\section{Conclusions}

A common practice for late blight control by large potatogrowing companies results in more fungicide applications than required, so expensive fungicides are often applied in situations where no significant disease development is observed. In this study we found a quantitative relationship between weather data and yield losses caused by a potato 
late blight. The developed mathematical model is intended to analyze the weather-based risk of disease development in different climatic regions. Use of this model in disease management may improve the management practice of late blight control on potato.

Acknowledgements This work was supported by the Governmental Program "Development of potato breeding and seed production in Russian Federation" (Block 8, project "Monitoring and study of a potato late blight in Russia: mapping of regions by the threat of possible epidemics and the costs of protective fungicide treatments").

Compliance with ethics guidelines Alexey Filippov, Maria Kuznetsova, Alexander Rogozhin, Olga Iakusheva, Valentina Demidova, and Natalia Statsyuk declare that they have no conflicts of interest or financial conflicts to disclose.

This article does not contain any studies with human or animal subjects performed by any of the authors.

\section{References}

1. Poswillo D E, Hamilton W J, Sopher D. The marmoset as an animal model for teratological research. Nature, 1972, 239(5373): 460 462

2. Benbrook C M, Sexson D L, Wyman S A, Stevenson W R, Lynch S, Wallendal J, Diercks S, van Haren R, Granadino C A. Developing a pesticide risk assessment tool to monitor progress in reducing reliance on high-risk pesticides. American Journal of Potato Research, 2002, 79(3): 183-199

3. Hansen J G, Koppel M, Valskyte A, Turka I, Kapsa J. Evaluation of foliar resistance in potato to Phytophthora infestans based on an international field trial network. Plant Pathology, 2005, 54(2): 169179

4. Cox A E, Large E C. Potato late blight epidemics throughout world. Agriculture Handbook. No. 174. Washington: USDA, 1960
5. Rogozhin A N, Filippov A V. Simulator for the comparison of fungicides, cultivar resistance, and DSS in the control of the late and early blight of potato. PPO-Special Report, 2012, 15: 237-238

6. Large E C. The interpretation of progress curves for potato blight and other plant diseases. Plant Pathology, 1952, 1(4): 109-117

7. van der Plank I E. Plant diseases: epidemics and control. New York: Academic Press, 1963

8. Gurevich B I, Filippov A V, Tverskoy D L. Comparison of two methods for estimation of potato yield losses caused by the foliar late blight development. Selskokhozyaistvennaya Biologiya, 1977, 12(3): 444-448 (in Russian)

9. Starodub I L, Gurevich B I. The use of a five-day weather forecast to calculate chances of the potato late blight outbreak. Meteorologiya $i$ gidrologiya, 1989, 7: 28-36 (in Russian)

10. Filippov A V, Kuznetsova M A, Rogozhin A N, Spiglazova S Yu, Smetanina T I, Derenko T A, Statsyuk N V. Efficacy of the VNIIFBlight decision support system in the control of potato late blight in Russia. PPO-Special Report, 2009, 13: 243-250

11. Evenhuis A, Bain R, Hausladen H, Nielsen B J, van der Berg W, Schepers H T A M. Fungicide evaluation to rate efficacy to control leaf late blight for the EuroBlight table. Report 3750328100. Wageningen: Wageningen Research, 2017

12. Bruhn J A, Fry W E. Analysis of potato late blight epidemiology by simulation modeling. Phytopathology, 1981, 71(6): 612-616

13. van Haren R J F, Jansen D M. LINBAL, light interception by active leaflayers: description and application of a late blight limited potato growth model for the Andean ecoregion. PPO-Special Report, 2003, 9: $133-178$

14. Hansen J G, Kessel G, Nærstad R, Schepers H, Nielsen B J, Lassen P. EuroBlight tool for the comparison of late blight sub-models Status and perspectives. PPO-Special Report, 2010, 14: 67-74

15. Hijmans R J, Forbes G A, Walker T S. Estimating the global severity of potato late blight with GIS-linked disease forecast models. Plant Pathology, 2000, 49(6): 697-705 